\title{
A PERIODIZAÇÃO NA HISTÓRIA DA LITERATURA BRASILEIRA
}

\author{
Oscar Fussato Nakasato / CEFET-PR
}

Resumo: Desde Ensaio sobre a literatura (1836), de Gonçalves de Magalhães, até a História da literatura brasileira (edição no Brasil em 1997), de Luciana Stegagno Picchio, a periodização da nossa literatura passou por transformações que indicam uma evolução. De uma periodização condicionada a fatos políticos ou simplesmente cronológica passa-se a uma periodização estilística. Durante muito tempo fatos como a independência do país foram usados como divisores de águas entre períodos literários. A partir de A literatura no Brasil (1955), de Afrânio Coutinho, principalmente, passa-se a reconhecer a literatura como uma realidade estética autônoma.

A periodização é, sem dúvida, um dos grandes problemas da historiografia literária, não obstante o desinteresse em relação ao tema ou mesmo a insignificância que lhe querem atribuir alguns. Não é rara a atitude docente em definir a periodização como "mero recurso didático". Aliás, muitos livros de literatura brasileira destinados ao $2^{\circ}$ grau partem desta idéia simplificadora ao estabelecerem o famoso quadro com datas, obras de transição e períodos literários. A periodização e o quadro correspondente podem, sim, ser recursos didáticos, mas não devem ser tratados com o desdém subjacente, neste caso, ao adjetivo "mero". Por outro lado, a periodização parece enfraquecer a idéia de continuidade da literatura.

A pouca importância atribuída à periodização decorre, geralmente, da dificuldade em se aprofundar a questão, que envolve problemas relacionados à literatura e à história, dualidade básica muitas vezes não levada em consideração. O problema não tem unanimidade de tratamento por parte dos próprios historiadores. A exposição dos sistemas periodológicos que apresentaremos na seqüência denuncia esta indefinição ao longo de um século e meio.

1836 - Ensaio sobre a literatura no Brasil - Domingos José Gonçalves de Magalhães

- Antes de 1808

- Depois de 1808

1841 - Bosquejo da história da poesia brasileira - Joaquim Norberto

- Séculos XVI e XVII

- Do início a meados do século XVIII

- Segunda metade do século XVIII

- Do início do século XIX até a época da independência

- Época da independência

- Época da reforma da poesia e do engrandecimento nacional

1843 - Da nacionalidade da literatura brasileira - Santiago Nunes Ribeiro

- 10 período: descobrimento até meados do século XVII 
- 2ํㅜ período: meados do século XVII (Cláudio Manoel da Costa) até 1830

- 3ํporíodo: a partir de 1830

1863 - Histoire de la litterature bresilienne - Ferdinand Wolf

- Da descoberta até o fim do século XVII

- Primeira metade do século XVIII

- Segunda metade do século XVIII

- Começo do século XVIII até 1840

- A partir de 1840

1872 - Resumo da história literária - Fernandes Pinheiro

- Fase de formação (séculos XVI e XVII)

- Fase de desenvolvimento (século XVII)

- Reforma (século XIX):

- $1^{\text {a }}$ época: do princípio do século até a independência

- $2^{\mathrm{a}}$ época: da independência até a maioridade de D. Pedro II

- 3época: tempos contemporâneos

1888 - História da literatura brasileira - Silvio Romero

- Período de formação (1500 - 1750)

- Período de desenvolvimento autonômico (1750 - 1830)

- Período de transformação romântica (1830 - 1870)

- Período de reação crítico-naturalista (1875 - 1893/1900)

1902 - História da literatura brasileira (2ª ed.) - Silvio Romero

- Período de formação (1592 - 1768)

- Período de desenvolvimento autonômico (1768 - 1836)

- Período de reação romântica (1836-1875)

- Período de reação crítica e naturalista e, depois, parnasiana e simbolista (1876 em diante) 1916 - História da literatura brasileira - José Veríssimo

- Período colonial 
- Período nacional

1919 - Pequena história da literatura brasileira - Ronald de Carvalho

- Período de formação (1500-1750)

- Período de transformação (1750-1830)

- Período autonômico (1830-1919)

1930 - História da literatura brasileira - Arthur Motta

- Época de formação

- Época de transformação

- Época de expansão autonômica:

- Fase do Romantismo

- Fase do Realismo

1931 - Noções de história da literatura brasileira - Afrânio Peixoto

- Literatura colonial

- Literatura reacionária

- Literatura emancipada

- Influências estrangeiras

1938 - História da literatura brasileira:Seus fundamentos econômicos - Nelson Werneck Sodré

- Literatura colonial

- Esboço de literatura nacional

- Literatura nacional

1955 - A literatura no Brasil - Afrânio Coutinho

- Era barroca

- Era neoclássica

- Era romântica

- Era realista

- Era de transição

- Era modernista 
- Era luso-brasileira: época do quinhentismo e do seiscentismo (1594-1724)

- Era luso-brasileira: época do setecentismo (1724-1808)

- Era nacional: época do Romantismo (1808-1868)

- Era nacional: época do Realismo (1868-1893)

- Era nacional: época do Simbolismo (1893-1922)

- Era nacional: época do Modernismo (1922-1945)

1959 - Formação da literatura brasileira - Antônio Cândido

-1750 a 1836

-1836 a 1880

1970 - História concisa da literatura brasileira - Alfredo Bosi

- A condição colonial

- Ecos do Barroco

- Arcádia e llustração

- O Romantismo

- O Realismo

- O Simbolismo

- Pré-modernismo e Modernismo

- Tendências contemporâneas

1997 - História da literatura brasileira - Luciana Stegagno Picchio (1)

- As grandezas do Brasil e catequese jesuítica

- O barroco brasileiro

- O século XVIII: das academias barrocas às sociedades independentistas

- O século XIX: Autonomia e independência

- O século XIX: O grande romantismo brasileiro

- O século XIX: Socialidade e Realismo

- O século XIX: Machado de Assis

- A poesia do Parnaso ao crepúsculo: realistas e parnasianos 
- A poesia do Parnaso ao crepúsculo: neoparnaianos e crepusculares

- A prosa do Parnaso ao crepúsculo: simbolistas, neoparnasianos e literatura regionalista

- A prosa do Parnaso ao crepúsculo: engajamento social e hedonismo verbal

- O Modernismo: os anos de vanguarda (1922-1930)

- Estabilização da consciência criadora nacional (1930-1945)

- As letras brasileiras de 1945 a 1964

- Dos anos do golpe ao fim do século

$\mathrm{Na}$ historiografia literária brasileira, o poeta de Suspiros poéticos e saudades é pioneiro na divisão periodológica com Ensaio sobre a literatura no Brasil, de 1836. Antes dele, Ferdinand Denis havia publicado em Paris o seu Résumé de l'histoire littéraire du Portugal, suivi du résumé de l' histoire littéraire du Brésil, em 1826, e Januário da Cunha Barbosa o Parnaso brasileiro, em 1831, mas o primeiro realizou somente um estudo genérico da nossa literatura, sem divisão em períodos, e a preocupação do segundo foi fazer uma coletânea. Esta intenção também presidiu o trabalho de outros nomes importantes, como Varnhagen, que em 1850 publicou Florilégio da poesia brasileira, com um esboço histórico, mas sem uma divisão sistemática.

Nestes começos da historiografia literária, os trabalhos participavam do espírito nacionalista, que constituía a espinha dorsal do pensamento crítico do século XIX. O que se propunha era realizar uma crítica empenhada, que pudesse registrar a existência de uma literatura brasileira e demonstrar a sua autonomia em relação à metrópole. Por isso não é de se estranhar que Gonçalves de Magalhães estabeleça 0 ano de 1808, tão significativo para a conquista da independência do Brasil, para marcar a transição entre os dois períodos em que divide a história da literatura brasileira. E Joaquim Norberto, que de uma forma geral estabelece uma periodização cronológica sem definição precisa de limites, sugere a proclamação da independência como a ponte transitória entre a quarta época e a quinta. Esse critério históricopolítico é retomado por outros historiadores. Fernandes Pinheiro usa a independência e a maioridade de D. Pedro II para a subdivisão da literatura do século XIX, José Veríssimo localiza em 1822 o início do Período nacional e Antonio Soares Amora determina o ano de 1808 para marcar o final da Era luso-brasileira e o início da Era nacional. E mesmo Luciana Stegagno Picchio, na sua contemporânea obra História da literatura brasileira, não consegue fugir da importância do fim da $2^{\text {a }}$ Guerra Mundial e do golpe militar de 1964 e usa estes fatos como linhas fronteiriças na periodização que realiza.

A dicotomia colônia/nação adotada na periodização literária revela a preocupação com autonomia, com características identificadoras de uma literatura brasileira. José Veríssimo, ao referir-se à literatura produzida no Período colonial, diz: "Necessariamente nasceu e desenvolveu-se a literatura no Brasil como rebento da portuguesa e seu reflexo."(2) Mais à frente defende que no Período nacional o país passa "a experimentar o influxo de outras e melhores culturas"(3), além do estímulo mais importante: "o sentimento nacional afinal consciente."(4) Antonio Soares Amora, por sua vez, explica a característica básica da literatura d a Era luso-brasileira: "seu paralelismo, em termos de quase identificação estética, com a literatura portuguesa /(...)/."(5) Depois, ao aludir à Era nacional, lembra que a literatura brasileira 
passa a "conquistar o seu carácter próprio e a receber influências variadas /(...)/."(6)

É interessante observar que a autonomia literária, para estes críticos, além de estar indissoluvelmente ligada à independência política e ao sentimento nacionalista, tem relação direta com a divergência em face da cultura lusíada. Tanto José Veríssimo quanto Antonio Soares Amora mencionam as influências de outras culturas, as quais não são repudiadas. $O$ que podemos compreender, a partir disso, é que a constituição de uma literatura autônoma não se realiza com o influxo de uma única cultura, que acabaria por sufocar as possibilidades de uma expressão mais peculiar. A abertura de canais para culturas diversas, por outro lado, pode fornecer subsídios para a formação da autonomia. Não se pode esquecer, contudo, da herança primordial e substancial da cultura portuguesa. Antonio Candido, que não se preocupa com a distinção entre literatura portuguesa e literatura brasileira em Formação da literatura brasileira, mas com a constituição de uma literatura propriamente dita, lembra que o problema da autonomia está superado, mas que se justificava no século passado, quando "agíamos, em relação a Portugal, como esses adolescentes mal seguros, que negam a dívida aos pais e chegam a mudar de sobrenome."(7)

Lucianna Stegagno Picchio também recusa a dicotomia literatura colonial/literatura nacional. Para ela, existe um único ponto de partida, que é o século XVI, quando começou a se produzir uma literatura de língua portuguesa dentro de coordenadas culturais brasileiras.

Outro critério usado na periodização da história literária é o da divisão puramente cronológica, que considera séculos e décadas. Este critério geralmente não é usado com exclusividade, mas para classificar uma parte da história literária. É o que fazem Joaquim Norberto, Ferdinand Wolf e Fernandes Pinheiro, que usam este esquema para os três primeiros séculos da vida brasileira, revelando uma dificuldade em estabelecer classificações periodológicas mais exatas para um tempo em que não existia propriamente uma literatura, como compreende Antônio Cândido.

Antonio Soares Amora também considera os séculos na subdivisão da sua Era luso-brasileira, usando termos como "quinhentismo", "seiscentismo" e "setecentismo", embora estabeleça para o início e o término de cada época datas mais específicas, que remetem a um fato significativo das letras brasileiras: 1594, início da Época do quinhetismo e do seiscentismo, é o ano das primeiras cartas informativas do Brasil do Padre Manuel da Nóbrega, e 1724, início da Época do setecentismo, marca a fundação da Academia Brasílica do Esquecidos. Para a subdivisão da Era nacional já usa o critério estilístico: Romantismo, Realismo, Simbolismo e Modernismo. A distinção de tratamento dado às duas eras também revela dificuldades relacionadas a uma caracterização mais precisa sobre o tipo de literatura praticado nos três primeiros séculos de vida brasileira.

Contra este método cronológico dos nossos historiadores literários reage Vianna Moog, que numa conferência de 1942 propõe um critério geográfico para a divisão da literatura brasileira. 0 crítico justifica a sua proposta dizendo que não há uma unidade homogênea e definida na nossa literatura. Na sugestão de Vianna Moog, há sete núcleos: Amazônia, Nordeste, Bahia, Minas, São Paulo, Rio Grande do Sul e Rio de Janeiro. Quanto ao processo cronológico, admite que "já é tempo de pô-la de lado"(8). Sua idéia, porém, sugere somente um modo distinto de estudar a literatura e não pode de forma nenhuma invalidar as histórias baseadas em divisões periodológicas.

Com Santiago Nunes Ribeiro, tem início uma série da historiografia literária brasileira que opta por um divisão tríplice. Seguem-no Fernandes Pinheiro, Ronald de Carvalho, Arthur Motta, 
Afrânio Peixoto, Nelson Werneck Sodré. Ainda poderíamos acrescentar a esta relação o nome de José Veríssimo, que aceita uma fase de transição entre o Período colonial e o Período nacional. De uma forma geral, estes autores situam o primeiro período nos séculos $\mathrm{XVI}, \mathrm{XVII} \mathrm{e}$ parte do século XVIII. A produção dos árcades mineiros marca o período de transição. $\mathrm{E} o$ terceiro é localizado a partir do século XIX, alguns determinando um ano específico para o seu início: 1808,1822... A exceção fica por conta de Afrânio Peixoto e Nelson Werneck Sodré. Aquele localiza o segundo período na primeira metade do século XIX e este a partir do Romantismo, determinando o início do terceiro período com o movimento modernista do século XX.

Os nomes dados aos três períodos também sugerem uma certahomogeneidade de compreensão sobre o que representa cada um deles. Vejamos: Fase de formação, Período de formação, Período colonial, Época de formação (para o primeiro período), Fase de desenvolvimento, Estádio de transição, Período de transformação, Época de transformação (para o segundo período) e Reforma, Período nacional, Período autonômico, Época de transformação autonômica (para o terceiro período). Ocorre que as nomenclaturas usadas por Afrânio Peixoto (Literatura colonial, Literatura reacionária e Literatura emancipada) e Nelson Werneck Sodré ( Literatura colonial, Esboço de literatura nacional e Literatura nacional) se aproximam daquelas usadas pelos outros autores, o que denuncia uma divergência de opiniões sobre a relação período cronológico/período de desenvolvimento literário. Por exemplo: enquanto José Veríssimo aponta a Plêiade mineira como responsável por uma fase de transição e a independência política como um marco significativo o suficiente para determinar o início de uma literatura nacional, Afrânio Peixoto encontra a fase de transição somente no início do Romantismo e uma literatura emancipada a partir do versos abolicionistas de Castro Alves. Nelson Werneck Sodré, por sua vez, reconhece uma literatura nacional somente no presente século, mais ou menos a partir do Movimento Modernista da década de 20.

As convergências e as divergências dos autores que optaram pela divisão tríplice mostram que a periodização não é arbitrária e não pode ser vista como um "mero recurso didático". O sistema periodológico revela um julgamento, um modo de ver o desenvolvimento da literatura. Até Arthur Motta (1930), era bastante freqüente entender como uma fase de "formação" o primeiro período da história literária brasileira. Afrânio Peixoto (1955) ataca tal classificação: "Ainda estamos na adolescência nacional. /(...)/ Não vejo, pois, formação acabada, nem reforma, nem transformação"(9). Paradoxalmente, o autor classifica o seu último período como Literatura emancipada. Antonio Candido, mais coerente, explica com bastante clareza o que entende por formação na sua obra historiográfica:

Mas há várias maneiras de se estudar literatura. Suponhamos que, para se configurar plenamente como sistema articulado, ela dependa da existência do triângulo "autor-obra-público", em interação dinâmica, e de uma certa continuidade da tradição. Sendo assim, a brasileira não nasce, é claro, mas se configura no decorrer do século XVIII, encorpando o processo formativo, que vinha de antes e continua depois. Foi este o pressuposto geral do livro, no que toca ao problema da divisão de 
períodos. Procurei verificá-lo através das obras dos escritores, postas em absoluto primeiro plano, desde o meado daquele século até o momento em que a nossa literatura aparece integrada, articulada com a sociedade, pesando e fazendo sentir a sua presença, isto é, no último quartel do século $\underline{\mathrm{XIX}} . "(10)$

Além de introduzir a divisão tríplice, a periodização de Santiago Nunes Ribeiro também inaugura um critério mais especificamente literário na classificação dos períodos, com o estabelecimento de autores de transição. Cláudio Manoel da Costa faz a ponte do primeiro para o segundo período e os padres Caldas e São Carlos e José Bonifácio deste para o terceiro.

O critério usado por Santiago Nunes Ribeiro é retomado por Silvio Romero na segunda edição de História da literatura brasileira, de 1902. Apesar de explicitar no próprio livro a sua posição sociológica, denunciando a sua formação na escola do determinismo positivista, Silvio Romero realiza uma periodização que estabelece os diversos blocos estilísticos usando um critério mais rigoroso em relação aos utilizados até então. As datas limítrofes são as da publicação de obras representativas da literatura brasileira. É verdade que foi passional ao indicar Ensaios de filosofia e crítica, de Tobias Barreto, de 1875, e o primeiro volume do Livro do centenário ( $A$ literatura brasileira), de sua própria autoria, de 1900, como iniciadores de novos períodos, mas as outras obras que sugere continuam até hoje como referências na periodização da literatura brasileira: Prosopopéia (1601, e não 1592, "data suposta da 1르 edição" para Silvio Romero), de Bento Teixeira, Obras poéticas (1768), de Cláudio Manoel da Costa, Suspiros poéticos e saudades (1836), de Gonçalves de Magalhães, e Broquéis (1893), de Cruz e Souza.

No prólogo da edição de 1902 da História da literatura brasileira, Silvio Romero ainda sugere duas novas divisões. Na primeira divide a história da literatura brasileira em Período clássico (1549-1836), Período romântico (1836-1870) e Período das reações antirromânticas (a partir de 1870). Na segunda, há um simplificação ainda maior: Período puramente clássico (1592-1792) e Período de transformações ulteriores (a partir de 1792). E conclui dizendo que "são, como se vê, quatro classificações e divisões diversas, o que importa afirmar não fazer o autor grande cabedal da que propôs no texto do livro e destas que aí ficam."(11) Dessa forma, procura sustentar a sua indefinição com a idéia de que a periodização não representa um fator importante na história da literatura. Mas a insignificância que atribui à questão não estará mascarando uma dificuldade em encontrar uma solução satisfatória para o problema?

Esta dificuldade foi assumida por Fernandes Pinheiro ao propor o seu sistema de periodização: "Adotando a divisão por períodos literários, na ordem do séculos, não desconhecemos a inconseqüência de semelhante classificação, visto como prolongam-se interminadamente no seguinte as idéias dominantes no anterior, não se sabendo ao certo quando acabam as antigas, nem se podendo fixar o ponto de partida das novas idéias."(12).

Preocupação semelhante demonstra José Veríssimo quando assevera que "uma escola literária não morre de todo porque outra a substitui."(13). O problema é sério, mas não é exclusivo da literatura. Qualquer classificação de disciplina que verse sobre a conduta e o pensamento humanos enfrenta esta dificuldade. Em se tratando de literatura, há duas atitudes bastante comuns frente ao problema: simplificá-lo, o que pode favorecer uma ilusória sensação de 
segurança, e ignorá-lo, por acreditá-lo sem solução.

Em A literatura no Brasil, Afrânio Countinho faz a opção pelo enfrentamento do problema. $\mathrm{Na}$ introdução o escritor critica as divisões periodológicas adotadas até então, compreendidas por ele como puramente cronológicas ou condicionadas à história política. Fundamentando sua posição nas idéias de René Wellek, Afrânio Coutinho formula uma periodização estilística: Barroco, Neoclassicismo, Arcadismo, Romantismo, Realismo, Naturalismo, Parnasianismo, Impressionismo e Modernismo. Dessa forma, reconhece a literatura como realidade estética autônoma. Ao mesmo tempo, admite o problema apontado por Fernandes Pinheiro e José Veríssimo e procura superá-lo através de um classificação que respeita mais a individualidade do escritor, sem dar às datas limítrofes a importância que antes tinham. É verdade que no interior do texto há referências a fatos representativos da literatura, com suas respectivas datas, mas não há mais um esquema rigoroso, que enquadre artistas e obras em períodos precisos. Dessa forma, há uma compreensão maior sobre o modo como os blocos literários se imbricam.

Antonio Candido dá prosseguimento ao trabalho de Afrânio Coutinho no que diz respeito a este imbricamento em Formação da literatura brasileira, realizando-o de maneira mais efetiva. No seu texto autores e obras se comunicam a todo momento. É claro que as aproximações no interior de um estilo de época são muito mais freqüentes, o que explica a própria idéia de período literário, em que prevalece um sistema de normas e padrões estilísticos. Mas a comunicação ocorre, também, entre os períodos, como podemos ver no exemplo que segue: "Junqueira Freire chora, se revolta, tem desejos insatisfeitos, clama na sua cela e traz desordenadamente este tumulto ao leitor. É mais apaixonado ou sincero do que, por exemplo, Tomás Gonzaga, escrevendo com emoção freada, na masmorra da llha das Cobras? De modo algum."(14)

A utilização do conceito de "continuidade" e de "dinamismo dialético" na relação de obras, autores e períodos aproxima Formação da literatura brasileira da idéia de poética sincrônica, de Roman Jakobson, retomada e desenvolvida por Haroldo de Campos em Por uma poética sincrônica. A proposta contida neste ensaio sugere uma revisão do panorama diacrônico da historiografia literária, estabelecendo uma ótica do presente para as obras, o que possibilitaria sincronizar, por exemplo, Sousândrade e a poesia concreta, segundo lembra o próprio Haroldo de Campos. No caso de Antonio Candido, a diacronia não é abandonada, já que há uma linha temporal presidindo os estudos que realiza, mas a história da literatura não é tratada como uma simples sucessão de períodos estilísticos.

O livro de Antonio Candido não é propriamente uma história da literatura brasileira, já que o autor prefere trabalhar uma parcela cronológica (1750-1880). Nem por isso deixa de fazer historiografia. Formação da literatura brasileira mostra bem a articulação das obras no tempo. E a escolha da fração cronológica é justificada através do termo "momentos decisivos", sub-título do livro, cuja idéia é desenvolvida no corpo do texto. O propósito de Antonio Candido é mostrar a importância dos dois períodos que estuda (Arcadismo e Romantismo) na formação da nossa literatura. E neste aspecto faz uma revisão historiográfica, pois desloca o conceito de formação no eixo temporal.

Antonio Candido privilegia o elemento estético e reconhece a autonomia da literatura, como quer Afrânio Coutinho. A divisão periodológica que estabelece em Formação da literatura brasileira revela essa postura. É o critério estilístico que aponta 1836 como divisor de águas, embora não haja rigor nesta proposta, pois é dada ênfase à idéia de movimento entre obras e 
períodos. Por outro lado, o autor não se esquece de que o fenômeno literário não pode ser isolado de um contexto histórico-social, ainda mais numa obra historiográfica. Antonio Candido diz que existe um estreita solidariedade entre o Arcadismo e o Romantismo, "pois se a atitude estética os separa radicalmente, a vocação histórica os aproxima, constituindo ambos um largo movimento /(...)/"(15) Ou seja: os "momentos decisivos" são marcados por obras que participam de um processo histórico, compromissadas com a vida nacional, e que acabarão por elaborar o sistema necessário à existência de uma "literatura propriamente dita".

Alfredo Bosi também usa o critério estilístico na divisão periodológica de História concisa da literatura brasileira, repetindo a mesma tendência em não definir datas limítrofes rigorosas. $O$ que difere a sua obra dos volumes de Afrânio Coutinho é o cuidado que teve em classificar as produções anteriores ao Arcadismo e posteriores à década de 30 do presente século. Ao chamar de Condição colonial e Ecos do Barroco os capítulos em que descreve a literatura produzida no Brasil até o aparecimento dos árcades, deixa clara a impossibilidade de uma classificação mais rigorosa para este período inicial. Retoma, de certa forma, as idéias de Antonio Candido, que chama de "manifestações literárias" as produções brasileiras até as Academias do século XVIII. E mesmo as de José Veríssimo, embora este seja mais cético em relação às nossas primeiras letras: "/(...)/ uma literatura que em trezentos anos da sua existência apagada e mesquinha não experimentou outras reações que as da Metrópole, servilmente seguida."(16) Os "ecos" a que se refere Alfredo Bosi também são do barroco europeu.

Quanto às produções mais recentes, Alfredo Bosi as classifica como Tendências contemporâneas. O termo é genérico, mas pode se alegar que também o Modernismo parte do mesmo princípio de contemporaneidade e permanece até hoje. Este período, porém, indica mais que o hodierno, o que faz com que obras escritas no Modernismo não sejam "modernas". A escolha de Alfredo Bosi se deve, em verdade, à falta de um termo mais específico.

De qualquer forma, ao estabelecer a divisão que distingue o Modernismo de Tendências contemporâneas, História concisa da literatura brasileira realiza um julgamento, o qual é explicitado na parte introdutória do último capítulo. Alfredo Bosi reconhece nas obras da década de 30 e 40 um amadurecimento da nossa literatura, uma superação do caráter aventureiro e romântico da década de 20 , embora não negue a contribuição do decênio marcado pela Semana de Arte Moderna.

A discussão sobre as possibilidades de divisão da literatura moderna é anterior a Alfredo Bosi. Em 1956, Alceu Amoroso Lima já propõe 1930 como limite para o Modernismo, denominando de Pós-modernismo a nova fase que se inicia naquela data. Ainda segundo o crítico, o ano de 1945 também marca o início de uma nova fase, o Neomodernismo. Afrânio Coutinho discorda da terminologia por acreditar que as alterações não foram tão radicais para justificarem os prefixos "pós" e "neo". Para ele, o caráter modernista preside toda produção desde 1922, apesar de concordar com a existência destas três fases dentro do movimento. A elas Luciana Stegagno Picchio ainda acrescenta uma quarta, que se inicia em 1964, com o golpe militar.

De Gonçalves de Magalhães a Luciana Stegagno Picchio há mudanças na periodização da literatura brasileira que indicam uma evolução em direção à compreensão da literatura como um fenômeno autonômico. De uma periodização condicionada a fatos políticos ou simplesmente cronológica (com divisões baseadas em séculos ou décadas), passa-se a uma periodização estilística. Isso não significa que antes a historiografia negasse o elemento estético e que hoje a política e a cronologia não sejam consideradas. Quando Gonçalves de Magalhães estabelece o 
ano de 1808 como divisor de águas entre os dois períodos que reconhece na literatura brasileira, ele o faz consciente das alterações que provoca a chegada da família real ao Brasil e suas conseqüências na vida literária do país. E Afrânio Coutinho, ao optar por dividir a literatura brasileira em estilos de época, não se esquece das inevitáveis relações entre o fenômeno literário e o desenvolvimento político-social, bem como da cronologia, já que considera a evolução estilística através dos tempos.

Qualquer que seja a solução que se encontre para o problema da periodologia, não se pode esquecer da dualidade básica que preside a questão: história e literatura. "Quando" e "onde" são perguntas fundamentais da história que necessitam de resposta. Afinal, a literatura, mesmo com características de atemporalidade e universalidade, está fatalmente ligada a um lugar e a um tempo. Esta certeza cria dificuldades quando estudamos obras ímpares, como as de Machado de Assis. Daí José Veríssimo e Luciana Stegagno Picchio reservarem um capítulo especial para o autor. Outros simplificam o problema, enquadrando o escritor na escola que é contemporânea às suas produções. Mas casos como o de Machado de Assis não desautorizam a periodologia. Alerta, porém, para a necessidade de priorizar sempre a literatura. Afinal, se a história responde às perguntas "onde" e "quando", a literatura constitui a resposta para a questão primordial: "o que".

\section{NOTAS}

1. A primeira edição desse livro é de 1972.

2. VERÍSSIMO, José. História da literatura brasileira. $5^{\mathfrak{a}}$ ed. Rio de Janeiro: José Olympio, 1969.

3. Ibid, p.2.

4. Ibid, p.6.

5. AMORA, Antonio Soares. História da literatura brasileira. Lisboa: Ática, 1961.

6. Ibid, p.24.

7. CANDIDO, Antonio. Formação da literatura brasileira. 6aㅡ ed. Belo Horizonte: Itatiaia, 1981, v.l.

8. VIANNA MOOG, Clodomir. Uma interpretação da literatura brasileira. In: Uma interpretação da literatura brasileira e outros escritos. Introdução de Clóvis Ramalhete. Rio de Janeiro: Delta, 1966. p.105-130.

9. PEIXOTO, Afrânio. Noções de história da literatura brasileira. Rio de Janeiro: Franscisco Alves, 1931.

10. CANDIDO, A. p.16. Obs: os grifos são nossos.

11. ROMERO, Sílvio. História da literatura brasileira. Tomo Primeiro. $3^{\mathrm{a}}$ ed. aumentada. Organizada e prefaciada por Nelson Romero. Rio de Janeiro: José Olympio, 1943.

12. LIMA, Alceu Amoroso. Introdução à literatura brasileira. 4⿳⺈冂䒑 ed. Rio de Janeiro: Agir, 1968.

13. VERÍSSIMO, J. p.9.

14. CANDIDO, A. v.2, p.157. 
15. CANDIDO, A. v.1, p.16.

16. VERÍSSIMO, J. p.3.

\section{REFERÊNCIAS BIBLIOGRÁFICAS}

01.AMORA, Antonio Soares. História da literatura brasileira. Lisboa: Ática, 1961.

02.BOSI, Alfredo. História concisa da literatura brasileira. $3^{a}$ ed. São Paulo: Cultrix, 1985.

03.CAMPOS, Haroldo de. Por uma poética sincrônica. In: $A$ arte no horizonte do provável. $2^{2}$ ed. São Paulo: Perspectiva, 1972. p.205-223.

04.CANDIDO, Antonio. Formação da literatura brasileira. $6^{\underline{a}}$ ed. Belo Horizonte: Itatiaia, 981, v.l.

05.CANDIDO, Antonio. Formação da literatura brasileira. $6^{\underline{a}}$ ed. Belo Horizonte: Itatiaia, 1981, v. II.

06. COUTINHO, Afrânio (org.). A literatura no Brasil. $2^{a}$ ed. Rio de Janeiro: Editorial Sul Americana, 1968, v. I.

07. COUTINHO, Afrânio. Introdução à literatura no Brasil. Rio de Janeiro: Livraria São José, 1968.

8. LIMA, Alceu Amoroso. Introdução à literatura brasileira. 4ํㅡㄹ ed. Rio de Janeiro: Agir, 1968.

9. MOTTA, Arthur. História da literatura brasileira: época de formação. São Paulo:

Companhia Editora Nacional, 1930.

10. PEIXOTO, Afrânio. Noções de história da literatura brasileira. Rio de Janeiro:

Franscisco Alves, 1931.

11. PICCHIO, Luciana Stegagno. História da literatura brasileira. Tradução por Pérola de Carvalho e Alice Kyoko. Rio de Janeiro: Nova Aguillar, 1997.

12. RIBEIRO, Santiago Nunes. Da nacionalidade da literatura brasileira. In: Caminhos do pensamento crítico (org. Afrânio Coutinho). Rio de Janeiro: Pallas/INL-MEC, 1972, v.1. p.42-72.

13.ROMERO, Sílvio. História da literatura brasileira. Tomo Primeiro. $3^{\mathrm{a}}$ ed. aumentada. Organizada e prefaciada por Nelson Romero. Rio de

Janeiro: José Olympio, 1943.

14. SODRÉ, Nelson Werneck. História da literatura brasileira: Seus fundamentos econômicos. 5ª ed. Rio de Janeiro: Civilização brasileira, 1969.

15. VERÍSSIMO, José. História da literatura brasileira. $5^{\mathrm{a}}$ ed. Rio de Janeiro: José Olympio, 1969.

16. VIANNA MOOG, Clodomir. Uma interpretação da literatura brasileira. In: Uma interpretação da literatura brasileira e outros escritos. Introdução de Clóvis Ramalhete. Rio de Janeiro: Delta, 1966. p.105-130. 
17. WOLF, Ferdinand. O Brasil literário; história da literatura brasileira. Tradução, prefácio e notas de Jamil Almansur Haddad. São Paulo: Companhia Editora Nacional, 1955. 